\title{
Loss of 13q14-q21 and Gain of 5p14-pter in the Progression of Leiomyosarcoma
}

Rubin Wang, M.D., Ph.D., Jenny C. Titley, B.Sc., Yong-Jie Lu, M.D., Ph.D., Brenda M. Summersgill, B.Sc., Julia A. Bridge, M.D., Cyril Fisher, M.D., D.Sc(Med)., F.R.C.Path., Janet Shipley, Ph.D.

Molecular Cytogenetics, Section of Molecular Carcinogenesis (RW, YJL, BMS, JS) and Section of Cancer Therapeutics (JCT), Institute of Cancer Research, Sutton, Surrey, United Kingdom; Department of Pathology, University of Nebraska Medical Center, Omaha, Nebraska (JAB); and Department of Histopathology (CF) and Section of Paediatric Oncology (YJL), Royal Marsden Hospital, Fulham Road, London, United Kingdom

Leiomyosarcomas of soft tissues are an aggressive group of tumors with a high incidence of recurrence. Little is known about the molecular genetic changes associated with clinical outcome. Therefore, we studied 28 leiomyosarcoma samples of similar grade using comparative genomic hybridization and DNA flow cytometry and identified a difference in survival time associated with ploidy status and the number of chromosomal aberrations. The average survival time was shown to decrease with increase in chromosomal aberrations identified using comparative genomic hybridization. The average survival time was shorter in the near-tetraploid group than in the diploid and triploid group. Gain of 5p14-pter was significantly more common in near-tetraploid tumors. The survival time of patients with near-tetraploidy together with gain of 5p14-pter was reduced, and $50 \%$ died within the 1st year. Furthermore, loss of 13q14-q21 was significantly more frequent in the <5-year than in the $>5$-year survival group $(P=.01)$. These results suggest that 13q14-q21 loss and 5p14-pter gain at diagnosis could be used to identify patients with leiomyosarcoma who are likely to have a shorter survival time and who might benefit from early treatment intensification.

KEY WORDS: Chromosome, Comparative genomic hybridization, Flow cytometry, Leiomyosarcoma, Progression.

Mod Pathol 2003;16(8):778-785

Copyright $(\odot 2003$ by The United States and Canadian Academy of Pathology, Inc.

VOL. 16, NO. 8, P. 778, 2003 Printed in the U.S.A

Date of acceptance: May 8, 2003.

This work is supported by Cancer Research UK: SP2328/03101.

Address reprint requests to: Janet Shipley, Ph.D., Molecular Cytogenetics Team, The Section of Molecular Carcinogenesis, Institute of Cancer Research, Male Urological Cancer Research Centre, 15 Cotswold Road, Sutton, Surrey, SM2 5NG, United Kingdom; fax: 44-20-8722-4278; e-mail: janet.shipley@icr.ac.uk.

DOI: 10.1097/01.MP.0000083648.45923.2B
Soft tissue sarcomas represent a heterogeneous group of mesenchymal malignancies, and previous studies of the relationship between molecular genetic data and outcome have been published. For example, patients with diploid retroperitoneal sarcomas had a better 10-year survival rate than those patients with aneuploid tumors (1). Patients with Ewing sarcomas harboring gains of chromosome 8 showed a slightly better clinical outcome, and deletions at 1 p36 were associated with an unfavorable outcome (2). Also, INK4A deletion has been found to be a significant negative prognostic factor in Ewing sarcoma (3). Malignant fibrous histiocytomas have been associated with $19 p+$ in cases that relapsed (4). Localized synovial sarcomas with the SYT-SSX2 fusion gene had a better prognosis than those with the SYT-SSX1 fusion gene (5). Mutations of TP53 and amplification of MDM2 have been associated with a more advanced clinicopathological stage in various tumor types (6-8). Also, investigation of these and other genes such as HRAS, KRAS, and $R B 1$ have suggested their involvement in soft tissue sarcomas $(9,10)$.

Leiomyosarcomas of soft tissue are a group of malignant tumors with low overall long-term survival rate. Therefore, it is important to understand the biological behavior of these tumors and to determine which tumors will have a more malignant course and thus need more intensive adjuvant therapy. Also, identifying and understanding the role of particular genes may lead to novel approaches to treat these tumors. It is widely accepted that most cancers are caused by the accumulation of genetic alterations (11-13). Deletion of 19p has been found in recurring leiomyosarcomas in a single case (14). An increase in copy number changes has been associated with tumor size of leiomyosarcoma (15).

In order to investigate whether any apparent differences in clinical outcome of leiomyosarcoma are associated with molecular cytogenetic changes, we 
used comparative genomic hybridization (CGH) to detect genomic imbalances and DNA flow cytometry to identify DNA ploidy alterations in wellcharacterized leiomyosarcoma samples.

\section{MATERIALS AND METHODS}

\section{Material}

A total of 28 samples from patients with a diagnosis of leiomyosarcoma was available for this study, and the samples' clinicopathological details are shown in Table 1. Diagnosis was made on the basis of immunohistochemical positivity in most cases for smooth muscle actin, desmin, and h-caldesmon combined with appropriate morphologic features (16). Both fresh samples from surgical resections that were snap-frozen immediately after surgical removal and formalin-fixed, paraffinembedded tissue were obtained from the Royal Marsden NHS Trust. The cases in which the follow-up time was sufficient were divided into two groups by length of survival: more than and less than 5 years after diagnosis. The follow-up time was only sufficient in 20 cases. Blood from normal healthy volunteers was used for the preparation of normal metaphase chromosomes and control DNA for the $\mathrm{CGH}$ experiments. Normal thyroid gland cells were used as normal control for flow cytometric analysis.

\section{CGH Analysis}

CGH analysis was performed according to the protocol described by Kallioniemi et al. (17), with some modifications as described elsewhere (18). Briefly, tumor DNA was extracted from frozen tumor tissues and labeled by nick translation with rhodamine-11-dUTP. Labeled DNA fragments were in the size range of 600 to $2000 \mathrm{bp}$. Normal sexmatched reference DNAs were labeled with fluorescein-11-dUTP and co-hybridized with the labeled tumor DNA to normal male metaphase chromosome preparations. For the CGH analysis, a control normal to normal hybridization was performed, and the average normalized fluorescence intensity ratios and their standard deviations did not exceed 0.2 above or below 1. Chromosomal regions were interpreted as underrepresented when the average ratio was $<0.8$, as overrepresented when the average ratio was $>1.2$, and as amplified when the average ratio was $>1.5$. For each tumor sample, between 6 and 10 good-quality metaphases were analyzed using Quips CGH/karyotyper and Interpreter software (Vysis, IL).

\section{DNA Flow Cytometry}

Flow cytometric analysis was performed as described elsewhere (19). Two or three $50-\mu \mathrm{m}$ sec- tions from each block were placed in a small biopsy (curettings) cassette stored in xylene in glass containers. After rinsing in xylene and agitating well to ensure complete removal of paraffin wax, they were washed twice in $100 \%$ ethanol, once in $50 \%$ ethanol, and twice in phosphate buffered saline (PBS). If the tissue was particularly fibrous, they were incubated for 1 hour at $37^{\circ} \mathrm{C}$ in $1 \mathrm{mg} / \mathrm{mL}$ collagenase in PBS. The tissue was removed carefully from the cassette and placed in a tube suitable for centrifugation. $0.9 \% \mathrm{NaCl}$ and $0.5 \%$ pepsin adjusted to pH1.5 with $\mathrm{HCl}$ were added and incubated at $37^{\circ} \mathrm{C}$ for 1 hour. The samples were passed through a 23-gauge needle to break up any clumps. The nuclear suspension was washed once in PBS and suspended in PBS, $100 \mu \mathrm{g} / \mathrm{mL}$ RNase, and $40 \mu \mathrm{g} / \mathrm{mL}$ propidium iodide, then incubated for 30 minutes at $37^{\circ} \mathrm{C}$. The suspension was analyzed using a spectra-physics argon-ion laser (Hemel, Hempstead, UK) producing $200 \mathrm{~mW}$ at $488 \mathrm{~nm}$. The files were gated on a cytogram of red fluorescence peak versus area to exclude clumps and a histogram of red fluorescence area displayed. The DNA index (DI) was near-diploid at a DI of 1.1 to 1.4 , triploid at a DI of 1.4 to 1.6, hypotetraploid at a DI of 1.7 to 1.8 , tetraploid at a DI of 1.9 to 2.1 , and hypertetraploid at a DI of $>2.1(20)$.

\section{RESULTS}

CGH analysis revealed genomic copy number changes in all leiomyosarcoma cases, with gains being more frequently observed than losses (Table 1). The average number of chromosomal aberrations detected by CGH was much higher in the $<5$-year survival group than in the $>5$-year survival group (8.58 versus 4.43 , $t$ test, $P=.01$ ). The number of aberrations was inversely proportional to the survival time (Fig. 1). Loss of $13 \mathrm{q}$ material was the most frequently observed change in the $<5$-year survival group, and this was significantly higher than the rate in the $>5$-year survival group (10 of 13 [77\%] versus 1 of 7 [14\%], $P=.01$; Table 2; Fig. 2). Five of the tumors had lost most of 13q, but in the other five tumors the loss was partial and allowed definition of a smallest region of common loss at 13q14-21. Gain of 5p14-pter was significantly more common in near-tetraploid tumors (Table 3; Fig. 3). One case with high-level amplification (red to green ratio of $>1.5$ ) on $5 p$ and two cases with gain of the whole of chromosome 5 died within 1 year. The case with high-level amplification on $5 p$ had one of the shortest survival times of all cases with $5 p$ gain (2.7 mo). The follow-up time in a further three cases was less than 3 years. In these six cases, two of the tumors showed gain of the whole of chromosome 5, but in four tumors the gain was partial and allowed 


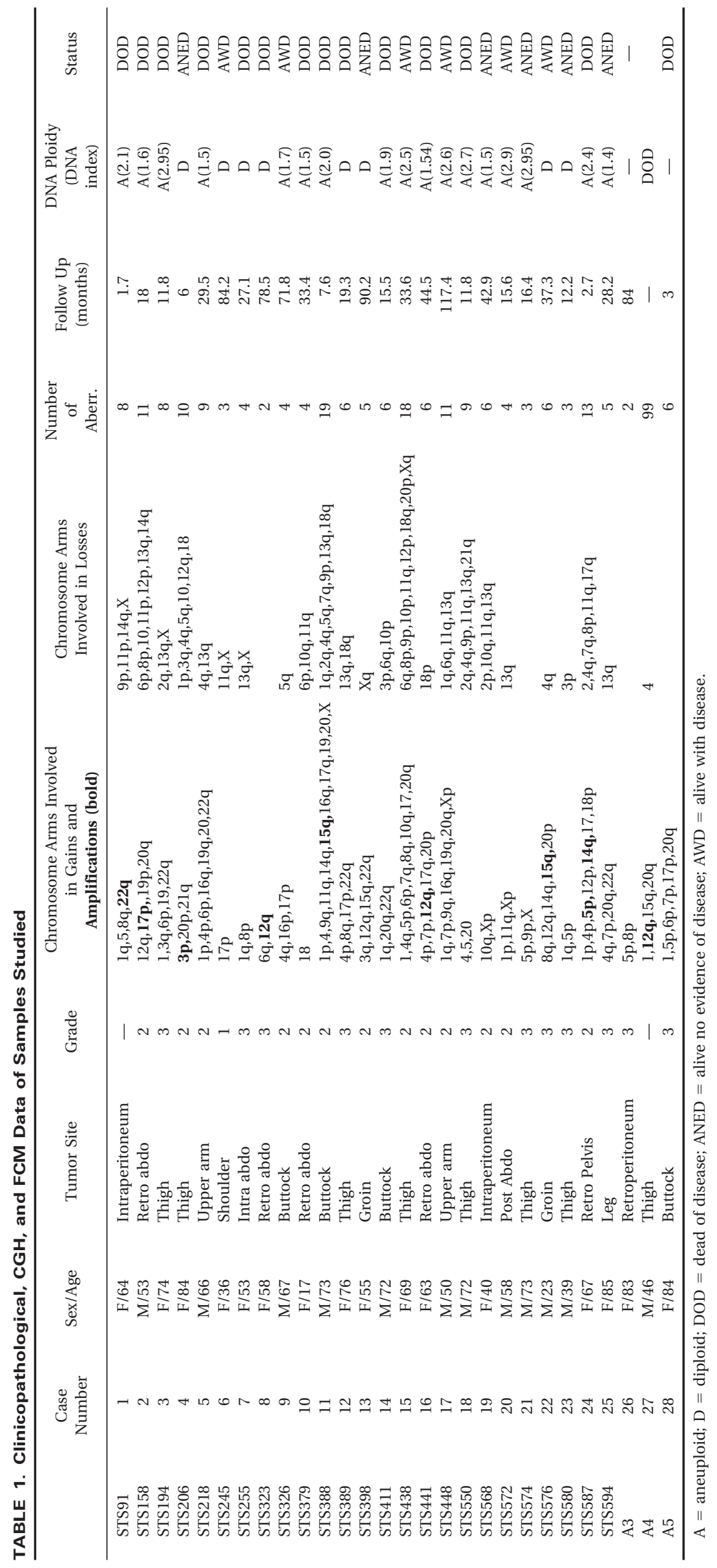




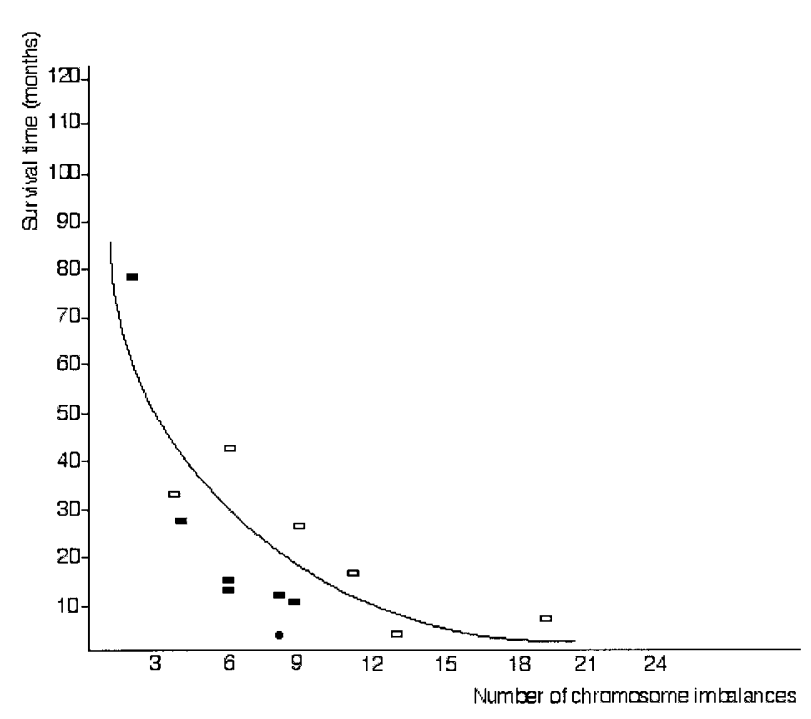

FIGURE 1. Relationship between number of chromosome imbalances identified by CGH analysis and survival time. Open square, Grade 2 leiomyosarcomas; filled square, Grade 3 leiomyosarcomas; filled circle, no grade available.

definition of a smallest region of common gain at 5 p14-pter. Other consistent changes included gains of material from chromosome regions 1q21, 4p16, $12 q 13-q 14,17 p 11.2,20 q 13.1$, and 22q and loss involving $4 \mathrm{q}, 11 \mathrm{q}$, and Xq. These changes were not significantly associated with outcome $(P>.05)$. The tumor grade, size, and site were also not significantly associated with outcome in the two groups $(P>.05)$, possibly because only one case was Grade 1.

Nuclear DNA measurement by flow cytometry revealed DNA aneuploidy and diploidy in 17 and 8 cases of leiomyosarcomas, respectively. Six of the aneuploid cases were triploid, and 11 of them were near-tetraploid. The DI of the aneuploid leiomyosarcoma cases ranged from 1.40 to 2.95. Approximately $68 \%$ of leiomyosarcomas showed clear evidence of an aneuploid DNA content by flow cytometry. Chromosomal imbalances were more frequent in near-tetraploid tumors than in diploid and triploid ones $(9.36$ versus $5.71, P<.02)$. The

TABLE 2. Frequencies of the Most Common Chromosomal Imbalances Found in 5-Year and Under 5-Year Survival Groups

\begin{tabular}{lrcc}
\hline $\begin{array}{c}\text { Chromosomal } \\
\text { imbalance }\end{array}$ & $\begin{array}{c}<5 \text { Years, } \\
n=13\end{array}$ & $\begin{array}{c}>5 \text { Years, } \\
n=7\end{array}$ & $\begin{array}{c}\text { Fisher's Exact } \\
\text { Test, } P \text { Value }\end{array}$ \\
\hline -13q14-q21 & $10(77 \%)$ & $1(14 \%)$ & $0.01^{*}$ \\
$+1 \mathrm{p} 31-\mathrm{p} 36.1$ & $5(38 \%)$ & $1(14 \%)$ & 0.35 \\
$+4 \mathrm{p} 16$ & $5(38 \%)$ & $1(14 \%)$ & 0.35 \\
$+22 \mathrm{q}$ & $5(38 \%)$ & $1(14 \%)$ & 0.35 \\
$+20 \mathrm{q} 13.1$ & $6(46 \%)$ & $2(29 \%)$ & 0.64 \\
$+1 \mathrm{q} 21$ & $5(38 \%)$ & $2(29 \%)$ & 0.87 \\
$+17 \mathrm{p} 11.2$ & $5(38 \%)$ & $2(29 \%)$ & 0.87 \\
- Xq21-qter & $3(23 \%)$ & $2(40 \%)$ & 0.97 \\
\hline
\end{tabular}

\footnotetext{
* Significant difference
}

average survival time was shorter in the neartetraploid group compared with the tumors with diploidy or triploidy (8.52 mo and 35.19 mo, t test, $P<.001$; Table 1).

\section{DISCUSSION}

We have combined CGH with flow cytometric analysis of a well-characterized series of leiomyosarcomas in order to identify any correlations between chromosomal changes and clinical outcome. As in previous studies of leiomyosarcoma $(13,21$, 22), many aberrations were detected. In this study, the most frequent gains were of $1 \mathrm{q} 21,4 \mathrm{p} 16,5 \mathrm{p}$, 12q13-q14, 17p11.2, 20q13.1, and 22q material, whereas the frequent losses involved $4 \mathrm{q}, 11 \mathrm{q}, 13 \mathrm{q}$, and Xq. The average number of chromosome imbalances found in the $>5$-year survival group was much lower than that in the $<5$-year survival group $(P=.01)$. The number of genomic alterations detected by CGH could be used as a predictor of tumor progression or recurrence; this is similar to the case in studies on a variety of other tumor types (23). DNA copy number changes were more frequent in aneuploid tumors than in diploid ones (24). Some data have not shown a relationship between survival and DNA ploidy (25), but some articles have shown that the ploidy may be used as a predictor of clinical outcome (1). DNA ploidy changes of euploidy to aneuploidy were closely correlated with the process of dedifferentiation in chondrosarcoma (26). Cellular DNA content analysis may be of value in assessing the malignant potential of diploid as well as aneuploid bone sarcomas (27). In this study, imbalances were more frequent in near-tetraploid tumors than in diploid or triploid ones. The correlations between DNA ploidy and chromosomal copy number changes suggest that leiomyosarcomas fall into two groups: first, diploid and triploid; second, near-tetraploid tumors. In leiomyosarcomas, the average survival time was significantly lower in the near-tetraploid group. This suggests that DNA ploidy may be used as an independent prognostic factor in leiomyosarcoma, as has been noted for other tumors (28-30).

Ten of the 13 samples in the $<5$-year survival group that were studied by CGH showed evidence for loss of 13q. Loss of 13q material was significantly associated with a shorter survival time (Table 2). Partial or complete deletion of $13 q$ was found, and the overlapping region of loss encompasses 13q14-q21, which includes the $R B 1$ and $D B M$ gene loci. Structural alteration of the $R B 1$ gene has frequently been seen in a number of cancers, including leiomyosarcoma and other sarcomas (31). As well as these genes, another as-yet unidentified tumor suppressor gene has been strongly suggested 


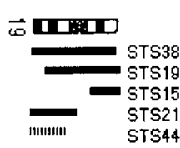

अप्माप

- STS44

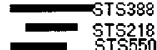

STS550
STS411

- $\quad$ A5

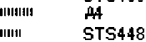

r.
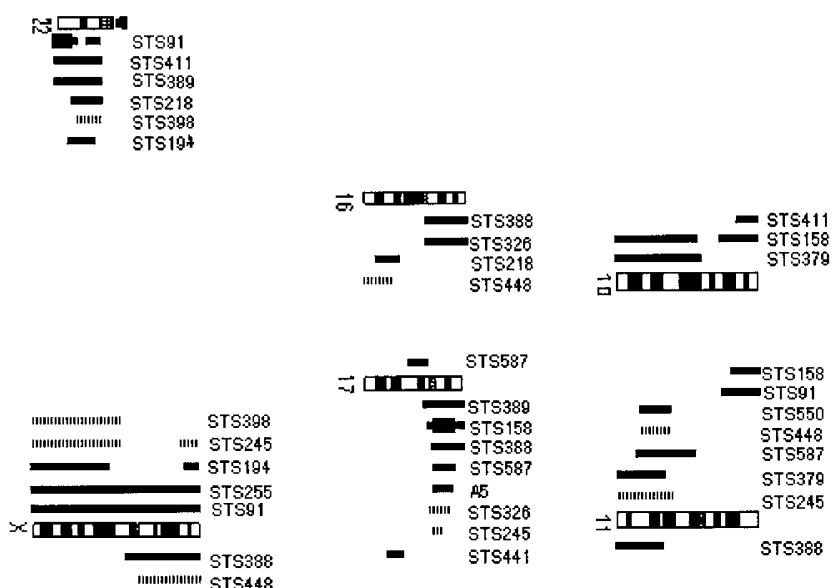

$\prec$

STS587
STS388
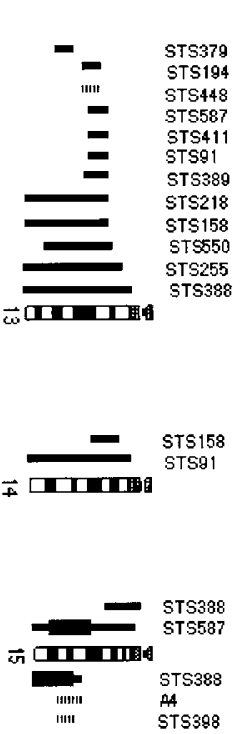

काI प्माप्ता

I.เก!I! $\quad$ STS 448

I"II!I!" STS448
$-\quad$ STS441
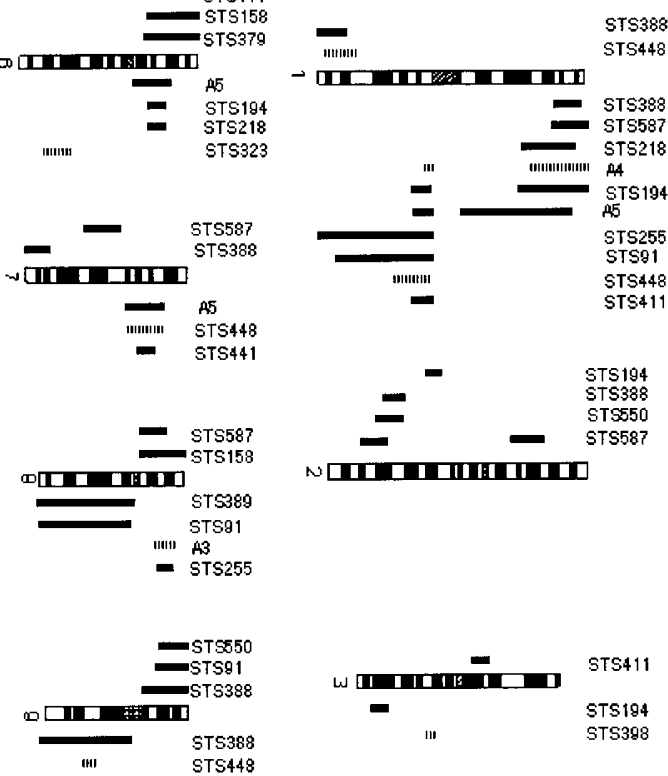

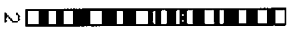

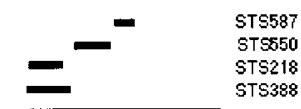

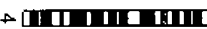
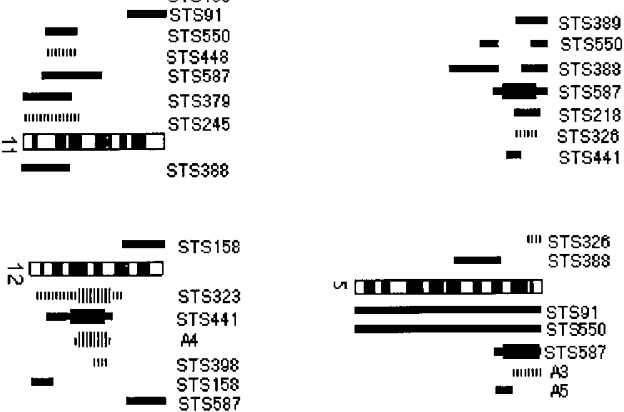

5388 STS 218

5194

$\mathrm{S} 25$

$\$ 41$

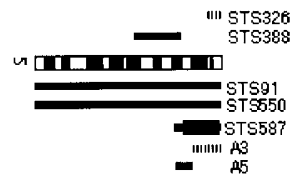

FIGURE 2. Summary of chromosome imbalances in the $>5$-year and $<5$-year survival groups identified by CGH analysis of the 20 samples of soft tissue leiomyosarcoma. Solid black lines represent the <5-year group, and hatched black lines represent the $>5$-year group. Lines to the left of chromosomes represent losses, and lines to the right of chromosomes represent gains. Thicker lines to the right of chromosomes represent regions of genomic amplification. The numbers above each line correspond to the identifiers in Table 1.

TABLE 3. Frequencies of the Most Common Chromosomal Imbalances Found in Near-Tetraploid and Diploid/Triploid Leiomyosarcomas

\begin{tabular}{|c|c|c|c|}
\hline Chromosomal Imbalance & $\begin{array}{c}\text { Near-Tetraploid, } \\
\quad n=11\end{array}$ & $\begin{array}{l}\text { Diploidy and Triploid, } \\
\qquad n=14\end{array}$ & $\begin{array}{c}\text { Fisher's Exact Test, } \\
P \text { Value }\end{array}$ \\
\hline$+5 p 14$-pter & $6(55 \%)$ & $1(7 \%)$ & $0.02 *$ \\
\hline$-9 \mathrm{p} 21-$ pter & $4(36 \%)$ & $0(0 \%)$ & 0.03 \\
\hline$-2 q 32$ & $3(27 \%)$ & $0(0 \%)$ & 0.07 \\
\hline$+12 q 13-q 14$ & $0(0 \%)$ & $3(21 \%)$ & 0.11 \\
\hline$-10 q 21-q 23$ & $0(0 \%)$ & $4(29 \%)$ & 0.11 \\
\hline +1p32-p36.1 & $4(36 \%)$ & $1(7 \%)$ & 0.13 \\
\hline$+\mathrm{Xp}+$ & $4(36 \%)$ & $1(7 \%)$ & 0.13 \\
\hline$+1 \mathrm{q} 21-\mathrm{q} 23$ & $5(45 \%)$ & $2(14 \%)$ & 0.18 \\
\hline
\end{tabular}

* Significant difference. 

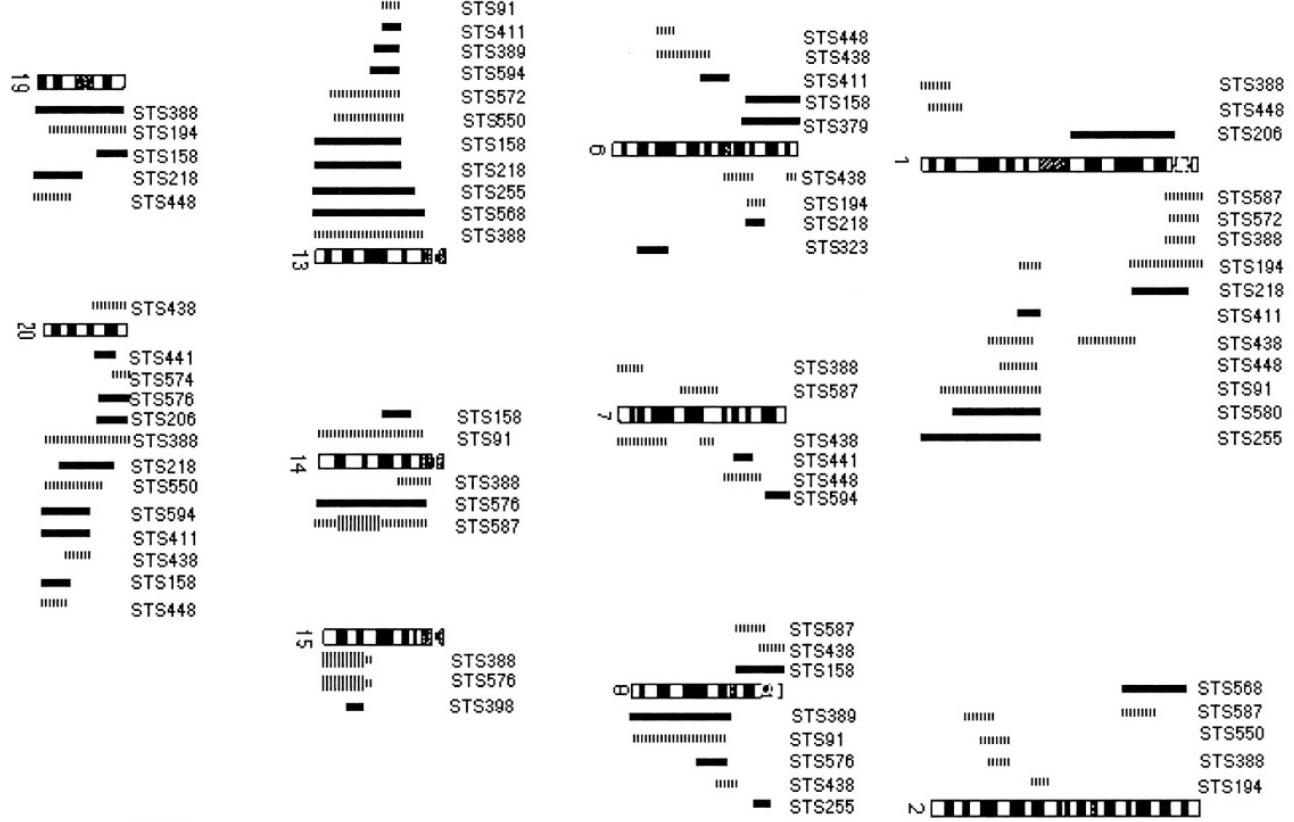

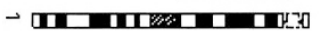

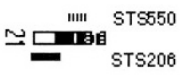

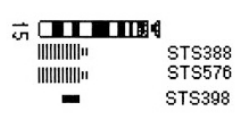

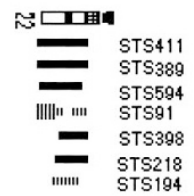

का प्राप्ता
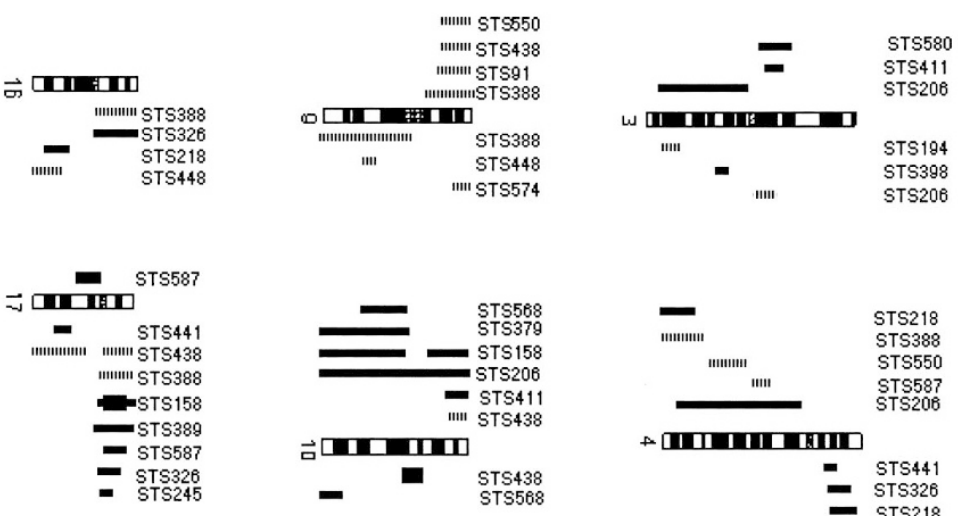

AाIIIIIIIID
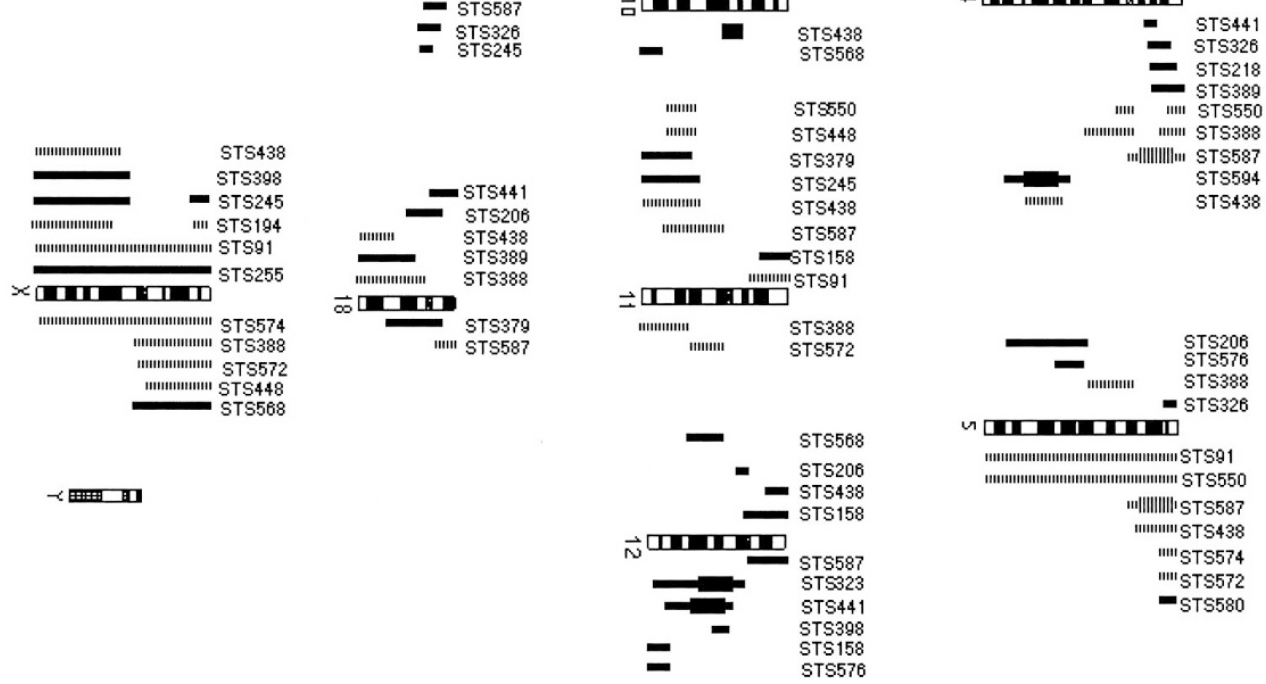

FIGURE 3. Summary of chromosome imbalances in the near-tetraploid group and in the diploid and triploid group identified by CGH analysis of 25 samples of soft tissue leiomyosarcoma. Solid black lines represent the diploid and triploid group, and hashed black lines represent the neartetraploid group. Lines to the left of chromosomes represent losses, and lines to the right of chromosomes represent gains. Thicker lines to the right of chromosomes represent regions of genomic amplification. The numbers above each line are the identifiers. 
in this region for involvement in other tumors (32, 33). Loss of chromosome 13 has previously been reported in 19 of the 27 leiomyosarcomas with a putative common region of loss of bands 13q14-21 (34). $13 q$ deletion has also been suggested as an early nonrandom event in uterine leiomyosarcoma (35), and loss of 13q14 was an independent prognostic factor in osteosarcomas and chondrosarcoma $(36,37)$. It is likely that the $13 q 14-q 21$ region harbors genes that play a role in the pathogenesis of leiomyosarcoma and other soft tissue sarcomas that may be related to a more aggressive phenotype.

Another candidate region is $5 \mathrm{p} 14$-pter, which is frequently gained in the near-tetraploid cases but rarely altered in diploid and triploid tumors. $5 p$ may harbor one or more critical oncogenes that may be involved in the progression of leiomyosarcoma. The survival time of patients with neartetraploidy together with gain of 5p14-pter was reduced significantly. Fifty percent died within a year. One case with amplification of $5 p$ only survived 2.7 months. The region involved encompasses a number of critical genes such as hTERT, DAT1, and ACR (38-40). Co-expression of survivin and hTERT transcripts has recently been shown to identify patients at high risk of tumor-related death in soft tissue sarcoma (41).

Overall, in this study we have identified chromosomal changes and ploidy status associated with poor prognosis in leiomyosarcoma. Loss of 13q14q21 and gain of 5p14-pter was found here to be associated with a shorter survival time. This suggests that it may be possible to define cytogenetic markers at diagnosis to identify a poorer risk group among leiomyosarcomas and ultimately to stratify treatment intensity.

Acknowledgments: The authors thank Omar Al Muderis for his help in retrieving clinicopathological data.

\section{REFERENCES}

1. Herman K, Gruchala A, Niezabitowski A, Glinski B, Lackowska B. Prognostic factors in retroperitoneal sarcomas: ploidy of DNA as a predictor of clinical outcome. J Surg Oncol 1999;71:32-5.

2. Hattinger CM, Rumpler S, Strehl S, Ambros IM, Zoubek A, Potschger U, et al. Prognostic impact of deletions at 1p36 and numerical aberrations in Ewing tumors. Genes Chromosomes Cancer 1999;24:243-54.

3. Wei G, Antonescu CR, de Alava E, Leung D, Huvos AG, Meyers PA, et al. Prognostic impact of INK4A deletion in Ewing sarcoma. Cancer 2000;89:793-9.

4. Rydholm A, Mandahl N, Heim S, Kreicbergs A, Willen H, Mitelman F. Malignant fibrous histiocytomas with a 19p+ marker chromosome have increased relapse rate. Genes Chromosomes Cancer 1990;2:296-9.
5. Kawai A, Woodruff J, Healey JH, Brennan MF, Antonescu CR, Ladanyi M. SYT-SSX gene fusion as a determinant of morphology and prognosis in synovial sarcoma. N Engl J Med 1998;338:153-60.

6. Lu ML, Wikman F, Orntoft TF, Charytonowicz E, Rabbani F, Zhang Z, et al. Impact of alterations affecting the p53 pathway in bladder cancer on clinical outcome, assessed by conventional and array-based methods. Clin Cancer Res 2002;8:171-9.

7. Ko JL, Cheng YW, Chang SL, Su JM, Chen CY, Lee H. MDM2 mRNA expression is a favorable prognostic factor in nonsmall-cell lung cancer. Int J Cancer 2000;89:265-70.

8. Patterson H, Gill S, Fisher C, Law MG, Jayatilake H, Fletcher CD, et al. Abnormalities of the p53 MDM2 and DCC genes in human leiomyosarcomas. Br J Cancer 1994;69:1052-8.

9. Yoo J, Robinson RA, Lee JY. H-ras and K-ras gene mutations in primary human soft tissue sarcoma: concomitant mutations of the ras genes. Mod Pathol 1999;12:775-80.

10. Pellin A, Boix-Ferrero J, Carpio D, Lopez-Terrada D, Carda C, Navarro S, et al. Molecular alterations of the RB1, TP53, and MDM2 genes in primary and xenografted human osteosarcomas. Diagn Mol Pathol 1997;6:333-41.

11. Suzuki M, Ohwada M, Saga Y, Saito S, Sato I. Are DNA mismatch repair deficiencies responsible for accumulation of genetic alterations in epithelial ovarian cancers? Cancer Genet Cytogenet 2001;124:152-8.

12. Fujiwara T, Stolker JM, Watanabe T, Rashid A, Longo P, Eshleman JR, et al. Accumulated clonal genetic alterations in familial and sporadic colorectal carcinomas with widespread instability in microsatellite sequences. Am J Pathol 1998;153: 1063-78.

13. Finlay GJ. Genetics, molecular biology and colorectal cancer. Mutat Res 1993;290:3-12.

14. Riva P, Dalpr L, Gualandri V, Volont M, Miozzo M, Malgara $\mathrm{R}$, et al. 19p deletion in recurring leiomyosarcoma lesions from the same patient. Cancer Genet Cytogenet 2000;119: 102-8.

15. El-Rifai W, Sarlomo-Rikala M, Knuutila S, Miettinen M. DNA copy number changes in development and progression in leiomyosarcomas of soft tissues. Am J Pathol 1998;153:98590.

16. Evans HL, Shipley J. Leiomyosarcoma. In: Fletcher CDM, Unni KK, Mertens F, editors. Pathology \& genetics: tumours of soft tissue and bone. Lyon, France: IARC Press; 2002. p. 131-4.

17. Kallioniemi OP, Kallioniemi A, Sudar D, Rutovitz D, Gray JW, Waldman F, et al. Comparative genomic hybridization: a rapid new method for detecting and mapping DNA amplification in tumors. Semin Cancer Biol 1993;4:41-6.

18. Weber-Hall S, Anderson J, McManus A, Abe S, Nojima T, Pinkerton R, et al. Gains, losses, and amplification of genomic material in rhabdomyosarcoma analyzed by comparative genomic hybridization. Cancer Res 1996;56:3220-4.

19. Ormerod MG. Analysis of DNA-general methods. In: Ormerod MG, editor. Flow cytometry. 3rd ed. Oxford, United Kingdom: Oxford University Press; 1994. p. 83-98.

20. Tanner MM, Karhu RA, Nupponen NN, Borg A, Baldetorp B, Pejovic T, et al. Genetic aberrations in hypodiploid breast cancer: frequent loss of chromosome 4 and amplification of cyclin D1 oncogene. Am J Pathol 1998;153:191-9.

21. Wang R, Lu YJ, Fisher C, Bridge JA, Shipley J. Characterization of chromosome aberrations associated with soft-tissue leiomyosarcomas by twenty-four-color karyotyping and comparative genomic hybridization analysis. Genes Chromosomes Cancer 2001;31:54-64.

22. Mandahl N, Fletcher CD, Dal Cin P, De Wever I, Mertens F, Mitelman F, et al. Comparative cytogenetic study of spindle cell and pleomorphic leiomyosarcomas of soft tissues: a 
report from the CHAMP Study Group. Cancer Genet Cytogenet 2000;116:66-73.

23. Zhao J, de Krijger RR, Meier D, Speel EJ, Saremaslani P, Muletta-Feurer S, et al. Genomic alterations in welldifferentiated gastrointestinal and bronchial neuroendocrine tumors (carcinoids): marked differences indicating diversity in molecular pathogenesis. Am J Pathol 2000;157: 1431-8.

24. Hashimoto Y, Oga A, Okami K, Imate Y, Yamashita Y, Sasaki $\mathrm{K}$. Relationship between cytogenetic aberrations by CGH coupled with tissue microdissection and DNA ploidy by laser scanning cytometry in head and neck squamous cell carcinoma. Cytometry 2000;40:161-6.

25. Plaat BE, Muntinghe FL, Molenaar WM, Hoekstra HJ, Bosveld HE, Dam A, et al. Clinical outcome of patients with previously untreated soft tissue sarcomas in relation to tumor grade, DNA ploidy and karyotype. Int J Cancer 1997;74: 396-402.

26. Murata H, Kusuzaki K, Kuzuhara A, Takeshita H, Nakamura $\mathrm{S}$, Tsuji $\mathrm{Y}$, et al. DNA ploidy alterations detected during dedifferentiation of periosteal chondrosarcoma. Anticancer Res 1999;19:2285-8.

27. Takeshita H, Kusuzaki K, Kuzuhara A, Tsuji Y, Ashihara T, Gebhardt MC, et al. Relationship between histologic grade and cytofluorometric cellular DNA and RNA content in primary bone tumors. Anticancer Res 2001;21:1271-7.

28. Ferno M, Baldetorp B, Borg A, Olsson H, Sigurdsson H, Killander D. Flow cytometric DNA index and S phase fraction in breast cancer in relation to other prognostic variables and to clinical outcome. Acta Oncol 1992;31:157-65.

29. Baba H, Korenaga D, Kakeji Y, Haraguchi M, Okamura T, Maehara Y. DNA ploidy and its clinical implications in gastric cancer. Surgery 2002;131:S63-70.

30. Abou-Rebyeh H, Borgmann V, Nagel R, Al-Abadi H. DNA ploidy is a valuable predictor for prognosis of patients with resected renal cell carcinoma. Cancer 2001;92:2280-5.

31. Stratton MR, Williams S, Fisher C, Ball A, Westbury G, Gusterson BA, et al. Structural alterations of the RB1 gene in human soft tissue tumours. Br J Cancer 1989;60:202-5.
32. Huang XP, Wei F, Liu XY, Xu X, Hu H, Chen BS, et al. Allelic loss on 13q in esophageal squamous cell carcinomas from northern China. Cancer Lett 2002;185:87-94.

33. Ogawara K, Miyakawa A, Shiba M, Uzawa K, Watanabe T, Wang XL, et al. Allelic loss of chromosome 13q14.3 in human oral cancer: correlation with lymph node metastasis. Int J Cancer 1998;79:312-7.

34. Derre J, Lagace R, Nicolas A, Mairal A, Chibon F, Coindre JM, et al. Leiomyosarcomas and most malignant fibrous histiocytomas share very similar comparative genomic hybridization imbalances: an analysis of a series of 27 leiomyosarcomas. Lab Invest 2001;81:211-5.

35. Hu J, Khanna V, Jones M, Surti U. Genomic alterations in uterine leiomyosarcomas: potential markers for clinical diagnosis and prognosis. Genes Chromosomes Cancer 2001; 31:117-24.

36. Ozaki T, Schaefer KL, Wai D, Buerger H, Flege S, Lindner N, et al. Genetic imbalances revealed by comparative genomic hybridization in osteosarcomas. Int J Cancer 2002;102:35565.

37. Mandahl N, Gustafson P, Mertens F, Akerman M, Baldetorp $\mathrm{B}$, Gisselsson D, et al. Cytogenetic aberrations and their prognostic impact in chondrosarcoma. Genes Chromosomes Cancer 2002;33:188-200.

38. Saretzki G, Petersen S, Petersen I, Kolble K, von Zglinicki T. hTERT gene dosage correlates with telomerase activity in human lung cancer cell lines. Cancer Lett 2002;176:81-91.

39. Fuke S, Suo S, Takahashi N, Koike H, Sasagawa N, Ishiura S. The VNTR polymorphism of the human dopamine transporter (DAT1) gene affects gene expression. Pharmacogenomics J 2001;1:152-6.

40. Rettenberger G, Adham IM, Engel W, Klett C, Hameister H. Assignment of the porcine acrosin gene, ACR, to chromosome 5 p15 by fluorescence in situ hybridization (FISH). Mamm Genome 1995;6:60-1.

41. Wurl P, Kappler M, Meye A, Bartel F, Kohler T, Lautenschlager C, et al. Co-expression of survivin and TERT and risk of tumour-related death in patients with soft-tissue sarcoma. Lancet 2002;359:943-5. 